\title{
Discussing the Value of Collective Memory and Cultural Heritage Based on the Concept of Environmental Development in Taiwan
}
Ting-Lun, Huang ${ }^{1, a}$, Hsin-Chieh(James), Juan ${ }^{2, b}$, Hwa-Sheng, Gau ${ }^{3, \mathrm{c}}$ Hung-Jui, Lee $^{4, d}$,

${ }^{1,3}$ Graduate Institute of Cultural and Creative Industries Tajen University, Ping Tung, Taiwan, ROC

${ }^{2}$ Center General Education Tajen University, Ping Tung, Taiwan, ROC

${ }^{4}$ Department of Hospitality Management Tajen University, Ping Tung, Taiwan, ROC

aeric@tajen.edu.tw, bjamesjuan@tajen.edu.tw, chwasheng@tajen.edu.tw, dsungfung@tajen.edu.tw

Keywords: environmental development, cultural heritage, collective memory, cultural citizenship, cultural and creative industries.

\begin{abstract}
New ideas and thoughts of reuse and maintain of Taiwanese cultural heritage has only developed in these recent two decades. The definition of cultural heritage seems not being well understood by citizens in Taiwan, far more about the concepts and policies. Thus cultural heritage has normally been schemed out in environmental plan. Cultural environment so far is still lack of characterized spots, and the public has not been inspired by this issue. The very fundamental base of cultural heritage is the rebuild of collective memory. Very obvious experiences from past movements, such as reservation of Tai-Suger and military community, can demonstrate that ideology and localization have brought more citizens actions. Those actions emphasized on historical cluster and cultural scenery, and more importantly the meaning of cultural environment has been shown. By the process of cultural reservation, ancient architectures usually can be classified and protected in different rank of historic monuments. In this study, we look forward to seeing that more and more different types of civic cultural places and activities can be spotted by rebuild of communities and the discovery process of collective memories. If these types of application can collaborate with cultural and creative industries, this can be remarkable new era of Taiwanese environment development.
\end{abstract}

\section{Introduction}

The reservation of Military Community culture is recently growing up, and it triggers more concerns on the value of cultural heritage and collective memory [1]. We seem to feel that concerning of cultural heritage not only becomes the activities of minor elite, but also gradually turns to be the main issue between and citizens. This is indeed an impressive phenomenon for environmental developing scheme. Although the cultural heritage in Taiwan can be traced back from Japanese occupation era, the thoughts and policies about entire cultural reservation, especially the new ideas of reuse and maintenance, have just had attention in these two decades. Two phases of amending and legislating of jaw (2000 \& 2005) had built up the base for cultural heritage. However the public still has little understanding of its definition. Current cultural reservation concepts are also limitedly understood by the public. Thus the plan of environmental development is still lack of the concerns of cultural heritage and reservation. Attractive and characterized environment can not 
be widespread, far more to inspire the emphasis of collective memory of communities.

\section{Study area and analysis method}

In order to promote the understanding and emphasis of cultural environment, this study will begin on the concepts of introduction of international cultural heritage, and this study will also illustrate relevant developments in Taiwan by literature reviews. In addition, we would like to discuss the relationships amongst cultural heritage cases and environments. Furthermore the trend of community development integration will be analyzed relating cultural heritage reservation and citizenship. We would like to see more cultural essences can be promoted by the eternal development in entire environment.

\section{Result and Discussion}

\section{The development of concepts of cultural heritage reservation}

\section{(1) Would Natural and Cultural Heritage}

The United Nation Educational, Scientific and Cultural Organization (UNESCO) was founded on 16 November 1945, headquartered in Paris. Its theme is to make contributions to world peace and security by the cooperation of education, science and culture internationally. After WWII, precious cultural and natural heritages had been destroyed worldwide by the threats of wars, natural disasters, environmental calamities and industrial development. The "Convention Concerning the Protection of World Cultural and Natural Heritage", adopted by General Conference of UNESCO on 16 November 1972, listed the "world heritage sites" and established "World Monuments Fund" and "world heritage committee". The first time to define and categorize world heritage by UN is that UNESCO themes to protect the valuable world natural and cultural heritages by cooperation internationally and to promote that each nation should be responsible to protect heritages in its own nation. According to "Protection of intangible cultural heritage convention", first article mentioned that heritages mean the monuments of history, art, archaeology, science, ethnology, anthropology, groups of building and sites. The monuments mean that the outstanding art, historical and scientific universal value of architectures, memorable paintings and sculptures, steles or inscriptions on stone with archaeological elements and caves. Groups of buildings mean that the outstanding universal value can be found in the distributing or collective architectures which contain historical, art and scientific characters, homogeneity and location. The sites mean the outstanding universal value can be found in those areas where historical, art and scientific artifical creations exist, or the natures contain artificial creation.

\section{(2)The development of cultural heritages in Taiwan}

According to the protection mechanism of valuable world cultural and natural heritages of UNESCO, many concepts and experiences of managing can be good examples for us to learn. About the legislative process of cultural heritages in Taiwan, the path can be traced from the 'Law for the Historic Site, Places of Scenic Beauty and Natural Monuments' in Japanese occupation era. After WWII, KMT government retreated to Taiwan; the 'Cultural Heritage Preservation Act' 
became the accordance of cultural heritages reservation. The ruler of country in the time mainly focused on the "strike back at mainland China", and emphasized the legal constituted authority of mainland China. On the other hand, the local Taiwan original historic memories and contextual culture were reserved badly. In general, before 1970s, the concepts of cultural heritage were not built, and the system and technique were not well developed. Thus many precious cultural heritages were ruined by political ideology and urban development planning.

After withdraw from UN, the delicate international prestige has changed. Economical and democratic developments have inspired the local consciousness. In the meantime, the community movement of monumental reservation and the reuse of old buildings triggered the concepts of cultural heritage reservation. [2] The public start to think that over-emphasized economic development and urban planning can harm cultural heritages. More and more environmental actions start actively, such as, Taipei Lin An-Tai ancient house, Taipei Quan Ye Bank old building and Tainan county court district court. The new cultural heritage reservation started booming in Taiwan. 'The Law of Cultural heritage reservation' was legislated in 1982, which originated from the establishment of the Council for Cultural Affairs, Executive Yuan. The legislation was formed by the thoughts of monumental reservation and maintenance. In general, the law was referenced from Japan, and it had not adequately solved executive problems because of different national situations. It only basically and principally provided accordance for monumental reservation. [3]

The amending of 'The Law of Cultural heritage reservation' in 2000 not only reviewed the difficulties of execution of cultural heritages in previous two decades in Taiwan, but also referenced the world cultural heritage new concepts to fulfill the entire legal system and institutions of cultural heritage. New amending of law had added the new category of 'cultural landscape' to reserve. In article 20 of the law, new technique and engineering method can be adopted when necessary to do anti-seismic, anti-disaster, moisture resistance and anti-corruption to extend its life.

Generally, apart from 'The Law of Cultural heritage reservation', other administrative orders, such as 'The enforcement rules of the Law of Cultural heritage reservation' and 'the guidelines of examination of pointed monuments' were formed to rule by executive organizations.

By the definition of 'Law of Cultural heritage reservation', cultural heritage means the heritages can be pointed and registered by its historical, cultural, art and scientific value. Approximately it can be divided in 7 categories, such as (1) Monument, ancient architecture, village. (2) Sites. (3) Cultural landscape. (4) Traditional art. (5) Folk custom. (6) Antique. (7) natural landscape.

\section{Cultural Heritage and Environmental development}

\section{(1) Self-reflection of environmental changes}

According to current 'Law of Cultural heritage reservation', antiques, monuments, folk art, custom and relevant things which contain historical and cultural values can be categorized as cultural heritages including natural landscape and ancient architectures. The government has taken the concepts to do monuments and cultural heritage reservation for decades, and so on the public cognized these concepts narrowly on these sorts of things. However antiques, monuments, folk art, custom and relevant things are the contents of cultural heritages which should be legislatively 
reserved. Gradually these heritages of long term accumulated memories and life values are disappeared by ignorance of cultural heritage and environmental developments. So far our urban environment becomes boring places and buildings which lack of stories and collective memory.

In some local area, many places which are not categorized as monuments are full of historical, art and cultural architectures, such as traditional villages, residential houses, old streets, and ancient temples. These heritages record locally the developing histories and the traces of citizen life. In fact the reservation of these kinds of heritages can be equal to monumental reservation, if those spots can be well-reserved and combined with local industries. For example, the aboriginal cultures which are full of characteristics should be well-reserved and expanded, and this can be specific cultural resources of ethnic groups. Time brings up natural and cultural combination on human-history, human-space, human-environment and human-human relationships by its accumulation. On the other hand, if the value of society too much forces on seeking the economic developments, environmental concerns and cultural heritages will normally face the difficulties of reservation at least.

\section{(2) Construction of cultural environment}

Cultural heritages are continually accumulated on developing of society civilization. The work of cultural heritages reservation, reuse and management absolutely are the important strategies of the lasting of historical space. It also fulfills local area historical memory and creates cultural environments, especially in cities. In cities, we should pay more attention on thinking of the issue of cultural heritage reservation and reuse to find the capable solution. Take Taipei Yuan-Shan Villa as an example, it's the first case that was individually adopted on managing. The ninety year-old western style building becomes the Taipei Story House successfully depending on civil support and creation.[4] Many ancient well-designed spaces were created to combine life, culture, art and industry. The recreation gave new life for the building which had been unseen nearly a century. Now it becomes the place, a new cultural landscape, which reserves monument and provides recreation together.

By the development and transformation of era, re-build and molding of collative memory and are becoming one of the important foundation. We may see more and more protests coming up, such as Taisugar company reservation from the past, recent military community reservation. The meaning behind the movements is to emphasize the value of cultural environment, such as "historical settlement" and "cultural landscape".

\section{Practical Citizenship}

The effect of citizenship is not only emphasized on individuals, but is stressed on self-awareness of group consciousness. Its value is to practice common rights and individual obligation in group, as far as community of developing to be concerned. The concepts of requesting cultural citizenship can be traced from 2004 when the Council for Cultural Affairs started planning movements of cultural citizenship widespread. The Council for Cultural Affairs claims that the meaning of cultural citizenship is not only to request efficient cultural resources from government, but to protect the citizen right and responsibility which can be obtained supported and maintained in developing of 
culture. This might change the identity which was only in blood, ethnic group community, history and location. It can start from the viewpoint of culture and art to rebuild a common cultural and beautiful society.

In fact, the most important concept of cultural citizenship is the forming of 'public domain'. Public domain combines citizenship and cultural policies, and it urges the rights and essences of citizenship to full of cultural meaning. Moreover it makes citizen not only have the democratic ability and knowledge to practice political rights, but also have the cultural identification by the educational function of cultural policies.[5] To build cultural identification, to promote cultural life, to encourage cultural development and to appear the emphasis of culture is the rise of cultural level in entire citizen society.

\section{Cultural Environment and Community Development}

\section{(1). Cultural landscape and historical space}

According to "The Operational Guidelines for the Implementation of the World Heritage", the concepts of "cultural landscape", which Taiwan government also took the same concept to form new "The Law of Reservation of Cultural Heritage", had been formally legitimated in articles. In the Article 3 of current law, historical architectures can be categorized, such as old buildings, traditional villages, old streets, and other historical sites. Historical architectures are cultural heritages which represent social collective memory and those full of meaning no matter public or private.[6]

Chinese people have immigrated in Taiwan for over 300 years. They had been through Dutch, Spanish and Japanese occupation. Thus Taiwan has its own unique social history environment appeared in different occupation eras. Local Taiwanese architectures appear different styles and features in different eras because of the interaction of politics, economy, societies and policies Due to Taiwanese architectures come across different ears, styles and social economic cultures, the essences of architecture can be much diversified. Another important value is the collective memory that is hidden in these places. Those places, apart from religious and educational uses, are mostly houses and western buildings.

\section{(2)Community Empowerment and collective memory}

The policy of entire community empowerment has been operated for more than twenty years. Public issues are becoming the core value in constructing community. [7] Residents involving combined local or professional crew created community identification and self-belonging by knowing history of their own communities. Cultural landscapes and historical settlements are formed by this way.[8] By different phases of localization, means of cultural reservation have been changed from 'static display' to 'reuse reservation', such as old street reservation.

Especially, current community empowerments combine local industries and communitarianism to handle the point of cultural landscape and ancient architecture very well.[9] This model can be linked to the urban planning. By the integration of urban developing, tourism, biology and community creation industry, the developing of public collective memory of cultural heritage can be expected. [10] In face, those urban traditional villages should take these community empowerments 
to inspire more art, cultural groups to provide different reuse of spaces. [11] This can be the re-birth of ancient building as an art distraction area or cultural hall which exists cultural landscape, folk and art elements. This must be the public focus, and can be the foundation of sustainable development of community.

\section{Summary}

In these two decades, empowerments have been brought into many communities, and cultural citizenship has initiated. We noticed that many voices and requests about cultural environment coming from native areas. Therefore school education, government and private organizations work together to keep the empowerments in communities. However by the economic and civil development, we shall know that many precious cultural environments are rapidly disappeared by ignorance. If the collective memory is lacking, humanity might lose the chance to dialogue with environment, and the crisis of identification and distance among people will begin,

Although the rules of cultural heritage are well-formed by different phases in these decades in Taiwan, and the legal system and institutions are generally completed, the public still lacks of the concepts of constructing a cultural environment. Most of people think that old building spaces and architectures are the encumbrance of urban planning, and they don't see the unique historical character and the importance of molding the style of the city. Therefore we understand that cultural and environmental education is needed in schools and communities, and this education should be promoted.

We look forward to seeing more and more spaces and activities which don't possess legal cultural heritage. These spaces and activities are closer to the history and culture of citizen's daily life. The seeking process of past collective memory can inspire more attention in communities. If cultural heritages can collaborate with cultural and creative industries, that should be the new era of Taiwanese cultural environmental sustainable development.

\section{References}

[1] Wang Yu-Hsia (2015). Discussing the Preservative Policy of Military Dependent Village Based on the Point of Activation Use-A Case Study of Japanese Official Residences-Shengli New Residential Quarter in Pingtung City. Tajen University Master Dissertation. Taiwan.

[2] Huang Ting-lun (1997). An Analysis of the Environmental Issues. PressStore. Taiwan.

[3] Han Pao-teh (2001). Urgent Repair on Cultural Heritage Preservation Act. National policy monograph by the National Policy Foundation. Taiwan.

[4] Chen Guoci (2005). Regeneration monuments Taipei Story House. World Culture. Taipei.

[5] Wang Lirong(2006). Construction of cultural citizenship: cultural policy development and the full implementation of citizens. Journal of Public Administration. Taipei.

[6] Tsai Hsin-Chen (2015). The Adaptive Reuse of Unused Space-A Case Study of Developing Pier-2 Art Center. National Pingtung University of Management Science Journal. Taiwan.

[7] Lai Yin-ming(2015). Investigating the Value of Settlement Empowerment in Jiadong and Liugen 
Villages from the Cultural Environment Perspective. Tajen University Journal of International Liberal Studies. Taiwan.

[8] Zhou Jian(2005). The Changes of Social Movement in Historic Preservation during Taiwan's Postwar. National Taipei University of the Arts Master's thesis.

[9] Liu Xiao-rong(2006) The Study of characteristics in Development of Cultural Industries and Creative Industries. Master's thesis Sun Yat-sen Institute of Public Administration. Kaohsiung.

[10] Harold - Shineikafu(1996). Collective Construction of Urban Culture Space. Chong Hing Press. Taiwan.

[11] Huang Ting-lun (2014). To Discuss the Local Industrial and Creative Value for the Community Development in Taiwan. Advanced Materials Research. Switzerland. 